\title{
Remote Cerebellar Hemorrhage Presenting with Cerebellar Mutism after Spinal Surgery : An Unusual Case Report
}

\author{
Halil Murat Sen, M.D., ${ }^{1}$ Mustafa Guven, M.D., ${ }^{2}$ Adem Bozkurt Aras, M.D., ${ }^{2}$ Murat Cosar, M.D., Ph.D. ${ }^{2}$ \\ Departments of Neurology, Neurosurgery, Faculty of Medicine, Canakkale Onsekiz Mart University, Canakkale, Turkey
}

Dural injury during spinal surgery can subsequently give rise to a remote cerebellar hemorrhage (RCH). Although the incidence of such injury is low, the resulting hemorrhage can be life threatening. The mechanism underlying the formation of the hemorrhage is not known, but it is mostly thought to develop after venous infarction. Cerebellar mutism (CM) is a frequent complication of posterior fossa operations in children, but it is rarely seen in adults. The development of CM after an RCH has not been described. We describe the case of a 65 -year old female who lost cerebrospinal fluid after inadvertent opening of the dura during surgery. Computerized tomography performed when the patient became unable to speak revealed a bilateral cerebellar hemorrhage.

Key Words : Cerebellum · Hemorrhage $\cdot$ Mutism $\cdot$ Spine.

\section{INTRODUCTION}

The development of a remote cerebellar hemorrhage $(\mathrm{RCH})$ is a rarely seen but important life-threatening complication. Chadduck first described an RCH in $1981^{4)}$. All previous RCHs were due to inadvertent opening of the dura during surgery ${ }^{7,9-11)}$. The incidence of inadvertent dural opening is reported as $3.5-17.4 \%{ }^{13)}$. The incidence of RCHs after lumbar spinal operations is $0.08 \%{ }^{3)}$. Cerebellar mutism (CM) refers to a reduced or complete loss of the ability to speak. In addition to mutism, ataxia, hypotonia, and emotional lability have been observed in patients with CM. The mutism may be temporary, or it can be permanent, with long-term effects ${ }^{14}$. CM has mostly been reported after posterior fossa tumor operations. There are no previous reports of mutism presenting with $\mathrm{RCH}$. We describe a rare presentation of CM following an $\mathrm{RCH}$ in a patient following surgery.

\section{CASE REPORT}

A 65-year-old female patient presented to our clinic with lower back and left leg pain. L4-S1 spinal stenosis and segmental instability were identified on lumbar magnetic resonance imaging (MRI) and dynamic graphic scans of the patient. As a result, L4-S1 posterior transpedicular fixation and L4-5 total laminectomy were completed. During the operation, the dura was accidentally cut, and primary dural repair was performed. The patient woke from the anesthesia and was taken to the ward. A neurological examination was nor-

- Received : September 12, 2014 •Revised : December 29, 2014 •Accepted : January 5, 2015

- Address for reprints : Halil Murat Sen, M.D.

Department of Neurology, Canakkale Onsekiz Mart University, Faculty of Medicine, Canakkale 17100, Turkey

Tel : +90-532 67664 55, Fax : +90-286 26359 57, E-mail : hmuratsen@gmail.com

This is an Open Access article distributed under the terms of the Creative Commons Attribution Non-Commercial License (http://creativecommons.org/licenses/by-nc/4.0) which permits unrestricted non-commercial use, distribution, and reproduction in any medium, provided the original work is properly cited. 
mal. Four hours later, the patient was unable to speak and appeared confused. She was also unable to walk and began vomiting. Although unable to speak, the patient was able to respond to verbal commands. Computerized tomography (CT) of the brain revealed a bilateral cerebellar hemorrhage. The hemorrhagic area showed a typical zebra sign appearance. Air and lateral ventricle dilatation were observed in the frontal parasagittal area at the bilateral interhemispheric and suprasellar levels (Fig. 1). Four days later, the patient regained the ability to speak, although she showed dysarthria. Ten days later, her speech was completely normal. One month later, the patient's neurological examination and walking were completely normal. CT performed in the second month of followup revealed no hemorrhage in the affected area (Fig. 2).

\section{DISCUSSION}

After cranial and spinal operations, cranial hemorrhages remote from the area of surgery may develop. The hemorrhages
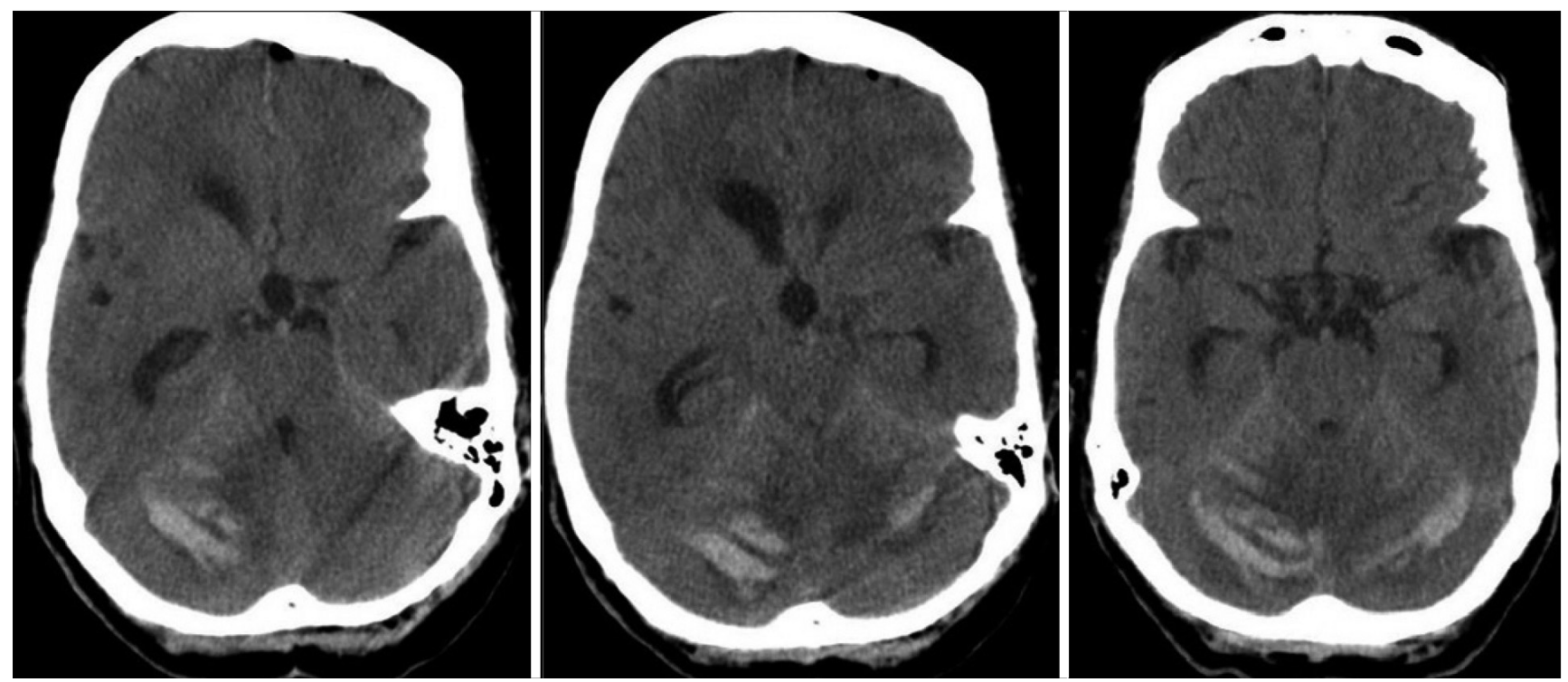

Fig. 1. A bilateral cerebellar hemorrhage (zebra sign), frontal and suprasellar pneumocephalus, and slight ventricular dilatation observed on postoperative $\mathrm{CT}$ : computerized tomography.
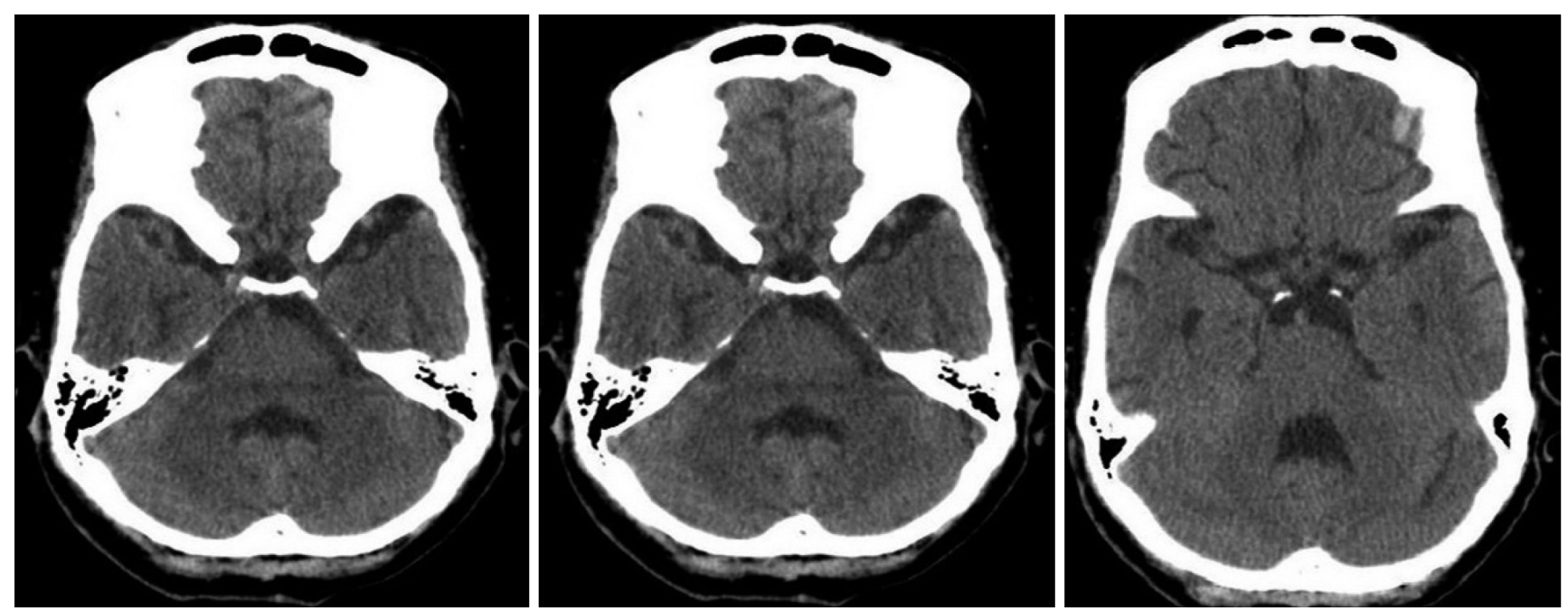

Fig. 2. Follow-up CT performed 2 months after the surgery showing no hemorrhage and a reduction in the ventricular size to a normal level. CT : computerized tomography. 
may be epidural, subdural, intracerebral, or intracerebellar. In 1981, Chadduck first described the development of an RCH after a spinal operation4). After that, there are only a few cases of remote cranial hemorrhage have been reported due the rarity, although it might result in fatal condition ${ }^{7-9)}$. The reported incidence of remote hemorrhages after spinal surgery $(0.08 \%)^{3)}$ may be higher than thought, as some cases may remain asymptomatic. According to one series, the prevalence of asymptomatic $\mathrm{RCH}$ was $0.8 \%{ }^{5)}$. The rate of asymptomatic cases is higher because imaging is carried out only in patients with symptoms ${ }^{2,5)}$.

Various factors, such as age, gender, pathology, and the type of surgery, have been put forward in the literature to explain the development of $\mathrm{RCHs}^{9,15)}$. However, there is no consensus on the exact mechanism. The common characteristic among nearly all RCH cases is inadvertent dural opening and subsequent cerebrospinal fluid (CSF) leakage ${ }^{7,9-11)}$. The incidence of this well-known complication is between 3.5 and $17.4 \%{ }^{13)}$. RCHs are thought to have a venous origin. The latter is supported by data showing that the arterial bleeding is unilateral and that the hemorrhage is in the upper vermis and cerebellar sulcus, the drainage area of the cerebellar veins ${ }^{11}$. Another hypothesis is that CSF loss causes caudal prolapse in the cerebellum, resulting in the development of cerebellar venous occlusion. This situation may cause secondary venous rupture and give rise to a hemorrhage in cases where reperfusion reoccurs or the venous pressure increases ${ }^{7)}$. In general, CT of the brain in cases of RCHs reveal typical zebra sign images, with hypodense and hyperdense irregular wavy lines resembling zebra skin ${ }^{3)}$.

$\mathrm{CM}$ is rare and is generally observed only in children after operations for posterior fossa tumors. The rate of CM in 500 adults following posterior fossa operations was $1.2 \%{ }^{6)}$. In children after medullablastoma operations, the incidence of $\mathrm{CM}$ was $24 \%{ }^{12)}$. There are no reports in the literature of the development of RCHs presenting with CM after spinal operations.

CM refers to a reduced or complete loss of speaking ability. In addition to mutism, ataxia, hypotonia, and emotional lability have been observed in CM. The mutism may be temporary, or it may be permanent, with long-term effects ${ }^{14)}$. Our case had temporary CM. The pathophysiological mechanism and anatomic correlation of CM are not well understood. CM is thought to develop after lesions in bilateral paravermian structures involving the dentate nucleus, vermis, lateral cerebellar hemisphere, and cerebrocortical pathways1). In our case, we think that the CM depends on affecting the bilateral paravermian structures (Fig. 3).

Generally, conservative medical treatment is sufficient for RCHs, and the long-term prognosis is good. However, some cases may require craniotomy of the posterior fossa and ventricular shunt surgery ${ }^{8)}$.

Usually, a headache is the most common symptom of CSF leakage. The patient should be monitored closely if a headache is accompanied by neurological complaints, and a neurological examination should be performed. As an intracranial hemorrhage is a life-threatening complication, $\mathrm{RCH}$ is to be suspected for patients having inadvertent dural injury. If those patients show any neurological changes, immediate imaging is recommended, in order to reduce mortality via the early diagnosis and treatment of the $\mathrm{RCH}$.
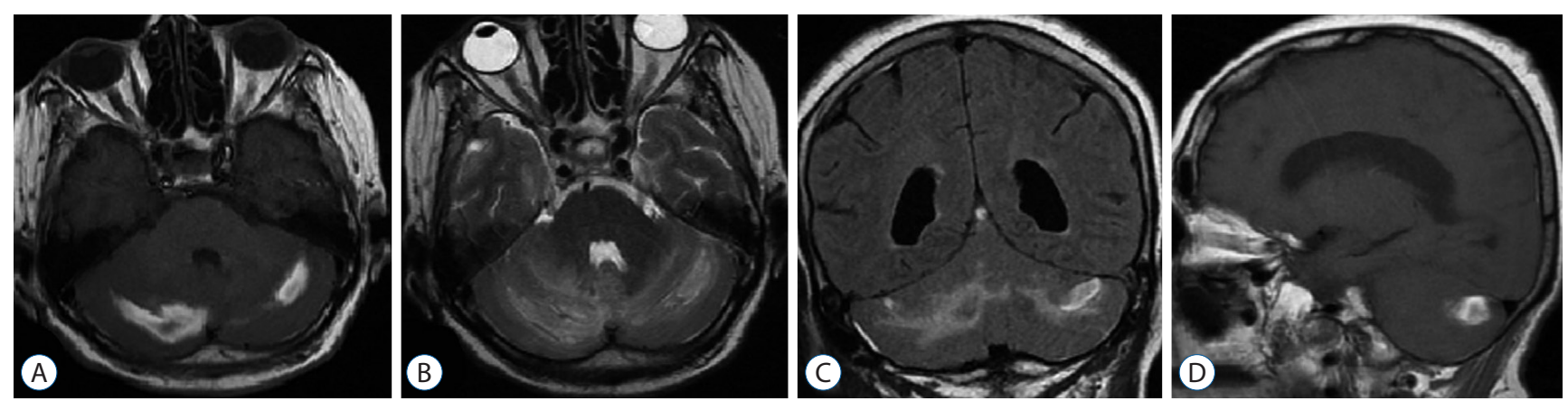

Fig. 3. Follow-up MRI performed 12 days after the surgery showing a bilateral hyperintense cerebellar lesion in accordance with a hemorrhage and slight ventricular dilatation. A : Axial T1-weighted image. B : Axial T2-weighted image. C : Coronal T2-weighted image. D : Sagittal T1-weighted image. $M R I$ : magnetic resonance imaging. 


\section{CONCLUSION}

$\mathrm{RCH}$ is to be considered in case of neurologic changes after spinal operations having dural injury. As RCHs can occur some time after the surgery, the patient's neurological status should be carefully monitored. As an RCH is a potentially fatal complication, it is important that the treatment begin as soon as possible. In addition, $\mathrm{RCH}$ might be revealed as cerebellar mutism, probably by affecting paravermian structures, as described in our case.

\section{References}

1. Afshar-Oromieh A, Linhart $H$, Podlesek D, Schrempf W, Schackert $G$, Krex D : Postoperative cerebellar mutism in adult patients with Lhermitte-Duclos disease. Neurosurg Rev 33 : 401-408, 2010

2. Cavanilles-Walker JM, Tomasi SO, Sgier F, Kröber M : Remote cerebellar haemorrhage after lumbar spine surgery : case report. Arch Orthop Trauma Surg 133 : 1645-1648, 2013

3. Cevik B, Kirbas I, Cakir B, Akin K, Teksam M : Remote cerebellar hemorrhage after lumbar spinal surgery. Eur J Radiol 70 : 7-9, 2009

4. Chadduck WM : Cerebellar hemorrhage complicating cervical laminectomy. Neurosurgery $9:$ 185-189, 1981

5. Dincer A, Özcan Ü, Kaya D, Usseli MI, Erzen C, Pamir MN : Asymptomatic remote cerebellar hemorrhage : $\mathrm{CT}$ and MRI findings. Cerebellum $11: 880-886,2012$
6. Dubey A, Sung WS, Shaya M, Patwardhan R, Willis B, Smith $D$, et al. : Complications of posterior cranial fossa surgery--an institutional experience of 500 patients. Surg Neurol $72:$ 369-375, 2009

7. Friedman JA, Ecker RD, Piepgras DG, Duke DA : Cerebellar hemorrhage after spinal surgery : report of two cases and literature review. Neurosurgery 50 : 1361-1363; discussion 1363-1364, 2002

8. Hashidate H, Kamimura M, Nakagawa H, Takahara K, Uchiyama S, Kato $\mathrm{H}$ : Cerebellar hemorrhage after spine surgery. J Orthop Sci 13 : 150 154,2008

9. Konya D, Ozgen S, Pamir MN : Cerebellar hemorrhage after spinal surgery : case report and review of the literature. Eur Spine J 15 : 95-99, 2006

10. Lee HY, Kim SH, So KY : Seizure and delayed emergence from anesthesia resulting from remote cerebellar hemorrhage after lumbar spine surgery -a case report-. Korean J Anesthesiol 63 : 270-273, 2012

11. Nam TK, Park SW, Min BK, Hwang SN : Remote cerebellar hemorrhage after lumbar spinal surgery. J Korean Neurosurg Soc 46 : 501-504, 2009

12. Robertson PL, Muraszko KM, Holmes EJ, Sposto R, Packer RJ, Gajjar A, et al. : Incidence and severity of postoperative cerebellar mutism syndrome in children with medulloblastoma : a prospective study by the Children's Oncology Group. J Neurosurg 105(6 Suppl) : 444-451, 2006

13. Tafazal SI, Sell PJ : Incidental durotomy in lumbar spine surgery : incidence and management. Eur Spine J 14 : 287-290, 2005

14. Wells EM, Walsh KS, Khademian ZP, Keating RF, Packer RJ : The cerebellar mutism syndrome and its relation to cerebellar cognitive function and the cerebellar cognitive affective disorder. Dev Disabil Res Rev $14: 221-228,2008$

15. Yoo JC, Choi JJ, Lee DW, Lee $S$ : Remote cerebellar hemorrhage after intradural disc surgery. J Korean Neurosurg Soc 53 : 118-120, 2013 